\title{
Fluidisation of iron-based oxygen carrier for chemical looping combustion
}

\author{
Gabriela Berkowicz ${ }^{1, *}$, and Magdalena Miłkoś ${ }^{1}$ \\ ${ }^{1}$ Cracow University of Technology, Faculty of Chemical Engineering and Technology, \\ ul. Warszawska 24, 31-155 Cracow, Poland
}

\begin{abstract}
The study focuses on the fluidisation of an iron-based material for chemical looping combustion. The $\mathrm{Fe} / \mathrm{Fe}_{\mathrm{x}} \mathrm{O}_{\mathrm{y}}$ system can act as an oxygen carrier. This material can be used to transfer the oxygen in the chemical looping combustion ensuring easy $\mathrm{CO}_{2}$ sequestration during the process of burning the fuels. This kind of process would be possible only by introducing the oxygen carrier into a fluidised state. The purpose of the presented work is to determine the size of grains of an iron-based material and the minimum fluidisation velocity of the gas which can ensure a proper fluidisation of the material.
\end{abstract}

\author{
Nomenclature \\ $U_{m f}$ - minimum fluidisation velocity, $\mathrm{m} / \mathrm{s}$ \\ $d_{b o}$ - the size of the bubble coming out of the porous plate, $\mathrm{m}$ \\ $U_{0}$ - process gas velocity, $\mathrm{m} / \mathrm{s}$ \\ $d_{b m}$ - maximum size of the bubble, $\mathrm{m}$ \\ $d_{b}$ - diameter of the bubble at given bed height, $\mathrm{m}$ \\ $z$ - height of the bed, $\mathrm{m}$ \\ $d_{t}$ - diameter of the fluidisation column, $\mathrm{m}$
}

\section{Introduction}

Earth's climate undergoes major changes. In spite of many pro-ecological activities, a new record of $\mathrm{CO}_{2}$ concentration $(405.0 \pm 0.1 \mathrm{ppm})$ at Earth's surface was noted in 2017 [1]. It is $45 \%$ more in comparison to the pre-industrial times when the average $\mathrm{CO}_{2}$ level was at $280 \mathrm{ppm}$. There is no doubt that such an increase is the result of human activity. The burning of fossil fuels is the most important source of $\mathrm{CO}_{2}$ emissions. Refraining from fuel combustion with the current energy demand is difficult. However, $\mathrm{CO}_{2}$ does not have to stay in the atmosphere as there are several methods of its sequestration [2]. $\mathrm{CO}_{2}$ can be stored in the used oil and gas fields, in the deep coal beds, in the aquifers, or the deep sea bottom [3]. However, these actions are limited because of the high costs of $\mathrm{CO}_{2}$ separation from fuel gases and its compression to liquid form. The problem of the high $\mathrm{CO}_{2}$ dilution in the off-gas can be resolved by Chemical Looping Combustion (CLC).

\footnotetext{
* Corresponding author: gabriela.berkowicz@pk.edu.pl
} 
CLC technology involves two connected reactors: air and fuel (Fig. 1). In the fuel reactor, there is no air stream; the combustion of fuel takes place using the lattice oxygen from a solid carrier. As a consequence, the stream coming out of the fuel reactor contains only $\mathrm{CO}_{2}$ and $\mathrm{H}_{2} \mathrm{O}$. Water is a component that can be easily removed by condensation. To close the loop, the oxygen-depleted solid carrier is directed to the air reactor where the re-oxidation takes place. The compounds based on $\mathrm{Co}, \mathrm{Ni}, \mathrm{Cu}, \mathrm{Mn}, \mathrm{Fe}, \mathrm{Cd}$ have been tested as the oxygen carriers $[3,4]$. The main advantage of the iron oxides, in comparison to other oxides used in CLC technology, is their relatively low cost, the availability and the environmental compatibility. The Fe-based oxygen carrier compounds, including synthetic materials, natural iron ores are tested [5]. The use of iron-based material in CLC technology requires its stable fluidisation. Due to the high density of iron-based materials, achieving its fluidisation is not easy. The purpose of the present study was to determine the size of the iron-based oxygen carrier grains that can be fluidised and to determine the minimum fluidization velocity for them.

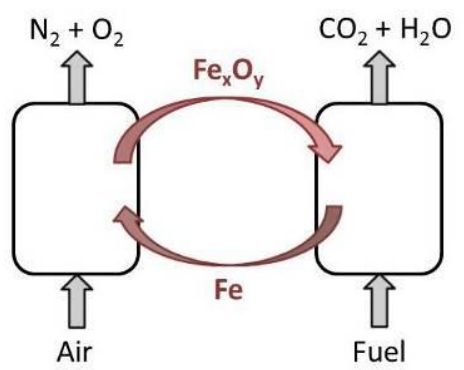

Fig. 1. Scheme of chemical looping combustion with Fe-based oxygen carrier.

\section{Experimental part}

\subsection{Material}

The fluidised bed material consists of $\mathrm{Fe}(80 \%$ mas. $), \mathrm{Fe}_{2} \mathrm{O}_{3}+\mathrm{FeO}(10 \%$ mas. $)$, and structural compounds $(10 \%$ mas. $)$, supplied by Grupa Azoty, Poland, was chosen as iron-based material that can serve as an oxygen carrier. It is a kind of alloy material which is obtained by melting the black iron ore and by its controlled cooling [6]. The commercial material has been crushed to the size of the grains below $250 \mu \mathrm{m}$.

\subsection{Apparatus}

The experimental arrangement is shown in Fig. 2A. A glass tube $(3.5 \mathrm{~cm}$ in diameter and $40.0 \mathrm{~cm}$ in height) was used as a fluidisation column (1). In the column, there was a glass frit (2) with a G0 porosity. The iron-based oxygen carrier (3) was placed in the reactor. The column was mounted on a three-neck round bottom flask (4). One of the necks was used to supply the fluidising gas (5). The gas was flowing through a mass flowmeter connected to a computer. The Terminal application (6) was used to monitor the gas flow rate. A pressure sensor MPXV5004DP (7) was placed on the second side neck. The DaqView application (8) was used to record the pressure drop. The change in the pressure drop caused by the glass frit (sieve bottom) has been determined by passing the gas at different flows through the empty reactor. In the tested velocity range, the dependence seems to be linear, however based on Darcy-Weisbach equation, the quadratic function has been assigned 
$\left(y=2.5288^{*} x^{2}+0.0376 * x\right)($ Fig. $2 B)$. The function was used to determine the pressure drop caused only by the iron-based oxygen carrier by subtracting the pressure drop caused by the presence of the sieve bottom from the measured pressure drop when the iron-based oxygen material was in the reactor.
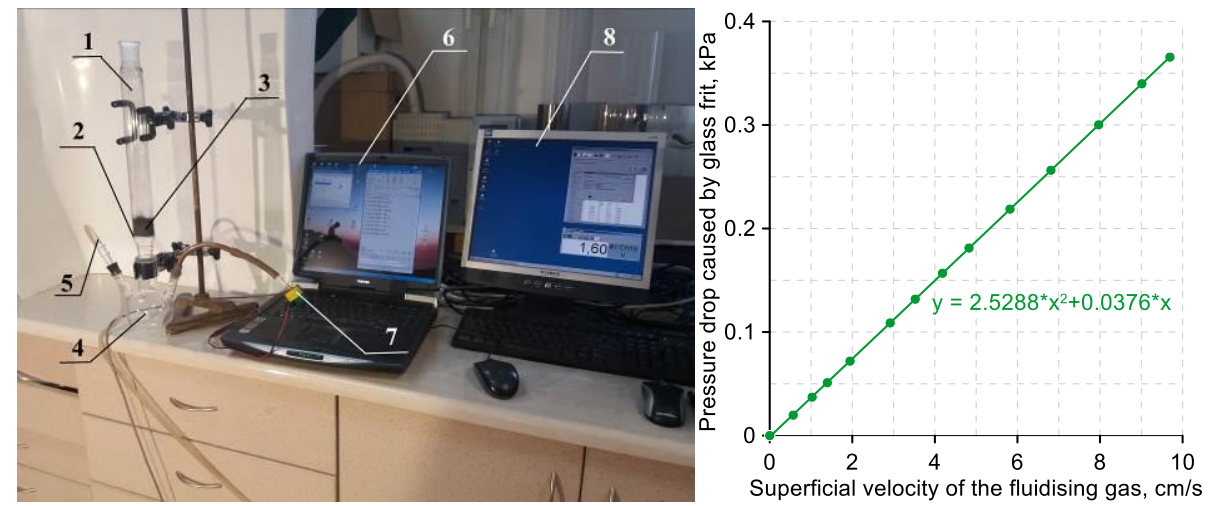

Fig. 2. Experimental arrangement (A) and pressure drop on glass frit (B)

1 - fluidised bed column, 2 - glass frit, 3 - iron-based oxygen carrier, 4 - three-neck round bottom flask, 5 - fluidising gas, 6 - the Terminal application - measurement of gas flow rate, 7 - a pressure sensor MPXV5004DP, 8 - the DaqView application - measurement of pressure drop.

\section{Results}

During the fluidisation test of the iron-based oxygen carrier with a grain size $<250 \mu \mathrm{m}$, it was observed that the most of the grains were stationary and they were arranged in a specific way, creating channels for the flowing gas. The faster the gas flows through the bed, the more channels appeared and the faster the gas was escaping. In the case of the chemical looping combustion, such a disturbance of the fluidisation process makes the reactants flowing through the bed to be in contact only with the iron-based oxygen carrier grains which form the inner walls of the channels. Apart from limiting access to oxygen and from limiting contact time, such performed process does not use the favourable features of the fluidised bed like uniform temperature, because of the grains that remain still. It was decided to prepare a narrower range of the iron-based material grain sizes (50-75, 75-100 and 100-140 $\mu \mathrm{m}$ ) for further tests. While testing the fluidisation of the iron-based oxygen carrier with a grain size $<50 \mu \mathrm{m}$, it was observed that only the upper layer of the bed underwent fluidisation (Fig. 3A). The channels were observed in the lower part of the bed. During fluidisation tests of other fractions, no disturbances were observed. The stills from the video of the proper fluidisation process were shown using the example of 50-75 $\mu \mathrm{m}$ fraction in Fig. 3B. The bubbling fluidisation has been achieved. The pressure drop was registered as a function of the velocity of the fluidising gas. Charts in Fig. 4 depict plots of pressure drop across the bed versus the superficial velocity of the fluidising gas. The arrow in the blue graphs indicates whether the curve has been received at increasing or at reducing the gas flow. The fraction $<50 \mu \mathrm{m}$ was disqualified from further research because of the channelling, and the minimum fluidisation velocity was not determined for it. For higher fractions, the minimum fluidisation velocities were determined as the point of the intersection of the lines characterizing the stationary bed and the lines describing the fluidised state (red dashed lines). 
A)

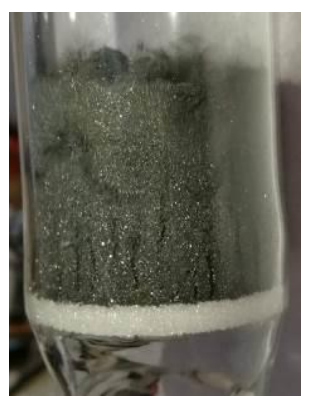

B)

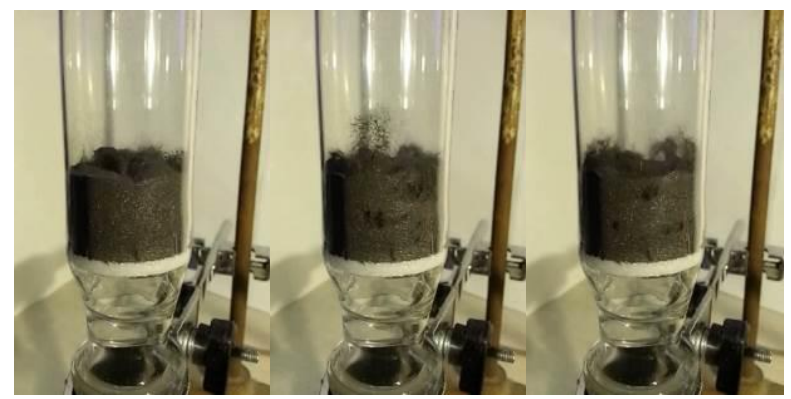

Fig. 3. Stills from the video of the fluidising test of iron-based oxygen fraction (A) fraction $<50 \mu \mathrm{m}$, (B) $50-75 \mu \mathrm{m}$ fraction.

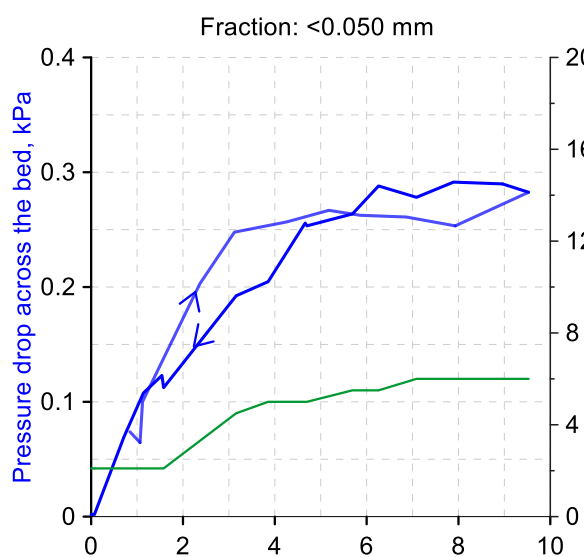

Superficial velocity of the fluidising gas, $\mathrm{cm} / \mathrm{s}$
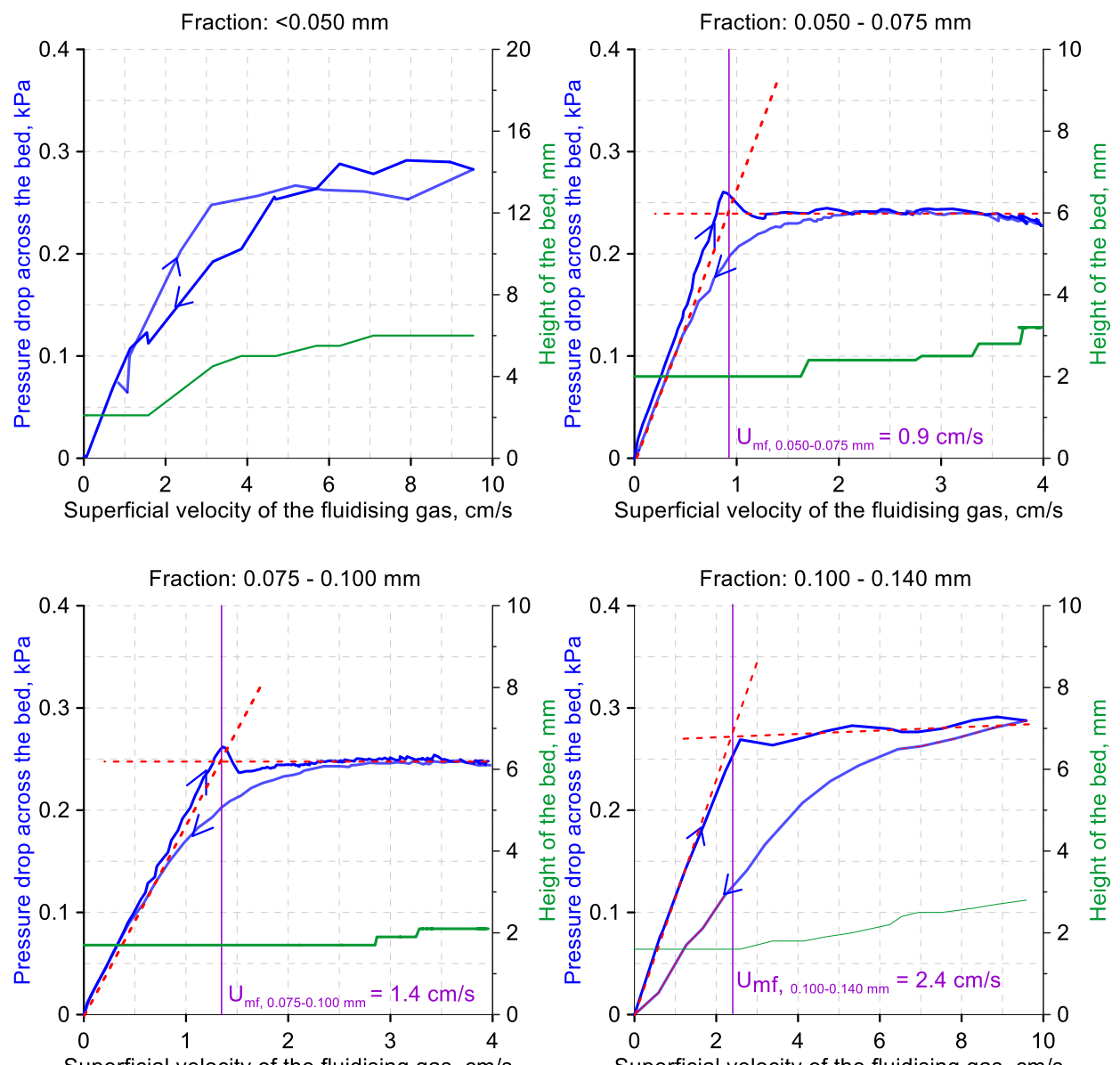

Superficial velocity of the fluidising gas, $\mathrm{cm} / \mathrm{s}$

Fig. 4. Plots of pressure drop across the bed versus the superficial velocity of the fluidising gas for different fractions of oxygen carrier. 
In this way, it was determined that the fractions $50-75,75-100 \mu \mathrm{m}$ could be stably fluidised at gas velocities of $0.9 \mathrm{~cm} / \mathrm{s}$ and $1.4 \mathrm{~cm} / \mathrm{s}$ (calculated on an empty cross-section of the apparatus) respectively. Additionally, the green lines in the charts show the expansion of the fluidised bed. A fluidisation curve obtained during fluidisation tests of iron-based oxygen carrier with a particle size of 100-140 $\mu \mathrm{m}$ differs from others. There was no characteristic 'hill', and the curves at the gas velocities, which were significantly below or above $U_{m \mathrm{f}}$, did not overlap each other. No disturbances of the fluidised state were observed during the process of fluidisation of this fraction of iron-based oxygen carrier. However, due to the shape of the obtained curve, the SEM images (Hitachi Model TM3000) were taken for this fraction. The photographs were taken at x100 and x600 magnifications (Fig. 5) to illustrate the general nature of grains and the surface of a single grain. The microscopic analysis revealed that some grains had a third dimension exceeding $140 \mu \mathrm{m}$. Some of these grains were marked with a red line in Fig. 5. The mesh of the sieve did not limit the third dimension. In the photo with x600 magnification, there is a grain whose dimension exceeds $200 \mu \mathrm{m}$ although the segregated fraction has stopped between the 100 and $140 \mu \mathrm{m}$ sieves. The grains have flat and sharp edges. Probably the method of raw material preparation makes this iron-based oxygen carrier crumbled unfavourably. In the SEM images (x600) one can observe a few tiny particles adhering to the grain. However, there was too few of them, so they did not affect the nature of fluidisation. This fraction could have been segregated during the fluidisation; hence a different course of the line of pressure drop can be observed when the flow of the gas was increased and decreased.

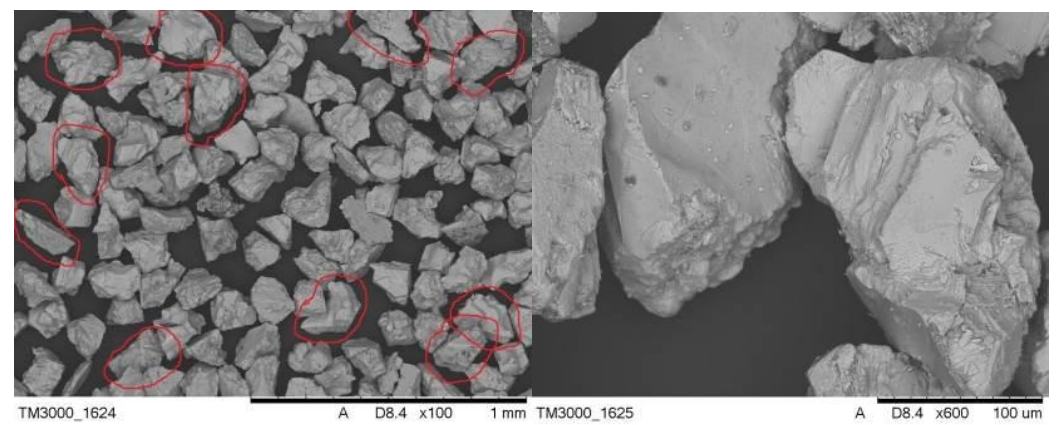

Fig. 5. The SEM images of fraction of iron-based oxygen carrier with grains $100-140 \mu \mathrm{m}$.

Experimentally determined minimum fluidisation velocities were highly consistent with the velocities that can be calculated from the Wen and Yu equations [7] (Table 1). The minimum bubbling velocities and the terminal velocities were also calculated. The terminal velocities limit the process. By exceeding this velocity one can lead to the pneumatic transport of grains. The minimum bubbling velocities were not much different from minimum fluidisation velocities. The bubbles were observed during the tests. The bubbles are not beneficial in CLC processes because they shorten the contact time between the fuel and the oxygen.

Considering the formula (1) that defines the size of the bubble coming from the porous bottom, the formula (2) that defines the maximum size of the bubble and the dependence between them given by formula (3), the sizes of the bubbles at given bed height were calculated from formula (4). Their tendencies are shown in Fig. 6. The calculations show that for the bed made of $50-75 \mu \mathrm{m}$ grains at the height of $1.5 \mathrm{~cm}$ the bubbles reach a diameter of $0.5 \mathrm{~cm}$. 
Table 1. Fluidization parameters of an iron-based oxygen carrier.

\begin{tabular}{|c|c|c|c|c|}
\hline $\begin{array}{c}\text { Fraction of } \\
\text { iron-based } \\
\text { oxygen carrier, } \\
\boldsymbol{\mu m}\end{array}$ & $\begin{array}{c}\text { Experimental } \\
\text { minimum } \\
\text { fluidisation } \\
\text { velocity, cm/s }\end{array}$ & $\begin{array}{c}\text { Minimum } \\
\text { fluidisation } \\
\text { velocity from } \\
\text { Wen and Yu } \\
\text { equation, } \mathbf{c m} / \mathbf{s}\end{array}$ & $\begin{array}{c}\text { Minimum } \\
\text { bubbling } \\
\text { velocity, cm/s }\end{array}$ & $\begin{array}{c}\text { Terminal } \\
\text { velocity, cm/s }\end{array}$ \\
\hline $50-70$ & 0.9 & 0.8 & 1.1 & 57.5 \\
\hline $75-100$ & 1.4 & 1.5 & 2.0 & 99.9 \\
\hline $100-140$ & 2.4 & 2.9 & 3.5 & 160.0 \\
\hline
\end{tabular}

$$
d_{b 0}=0,00376 \cdot\left(u-u_{m f}\right)^{2}
$$

$$
d_{b m}=0,65 \cdot\left[\frac{\pi}{4} \cdot d_{t}^{2} \cdot\left(u_{0}-u_{m f}\right)\right]^{0,4}
$$

$$
\frac{d_{b m}-d_{b}}{d_{b m}-d_{b 0}}=\exp \left(\frac{-0,3 z}{d_{t}}\right)
$$

$$
d_{b}=d_{b m}-\exp \left(-\frac{0,3 \cdot z}{d_{t}}\right) \cdot\left(d_{b m}-d_{b 0}\right)
$$

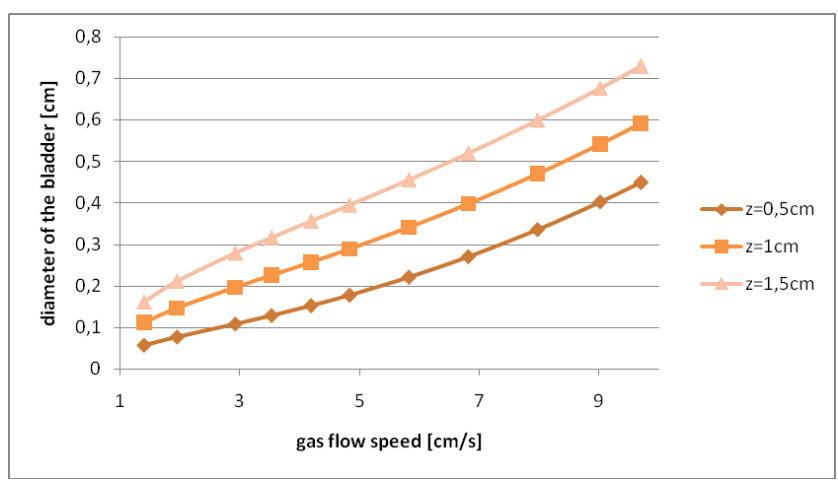

Fig. 6. The tendency to the growth of the bubble at different bed height depending on the gas flow velocity.

Experimentally there is no way to determine the minimum bubbling velocity. However, in order to check the reliability of the calculations concerning bubbling fluidisation, a single bubble flowing along the reactor wall was photographed. For this purpose, $30 \mathrm{~g}$ of iron-based oxygen carrier $(50-75 \mu \mathrm{m})$ was fluidised by air at a flow rate of $3.8 \mathrm{dm}^{3} / \mathrm{min}$ (superficial velocity $=7 \mathrm{~cm} / \mathrm{s}$ ). In Fig. 7 there is a photographed bubble at a bed height of $1.5 \mathrm{~cm}$ which has a diameter of about $0.5 \mathrm{~cm}$, and it is consistent with the calculation data using the above formulas. 


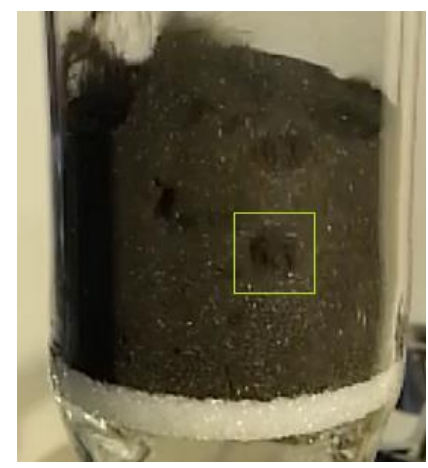

Fig. 7. The bubble at bed height of $1.5 \mathrm{~cm}$ with a diameter of $0.5 \mathrm{~cm}$.

\section{Conclusion}

To use commercially available $\mathrm{Fe} / \mathrm{Fe}_{2} \mathrm{O}_{3}$ material as an oxygen carrier in the Chemical Looping Combustion requires achieving stable fluidization of this material. For this purpose, it is necessary to separate a narrow range of grains diameter and getting rid of the finest fraction $<50 \mu \mathrm{m}$. A stable fluidised state was achieved for this oxygen carrier fraction with a grain size of 50-75 $\mu \mathrm{m}, 75-100 \mu \mathrm{m}$ and 100-140 $\mu \mathrm{m}$. Respectively 0.9 ; 1.4 and $2.4 \mathrm{~cm} / \mathrm{s}$ were the minimum fluidisation velocities for the fractions determined while carrying out the experimental work. These values are consistent with the values calculated from the Wen and $\mathrm{Yu}$ equations, which means that this correlation can be successfully used for the further determination of the minimum fluidisation velocities rate of the iron-based oxygen carrier also at higher temperatures. Due to the fact that the terminal velocities of iron-based oxygen carrier equal 57.5; 99.9 and $160.0 \mathrm{~cm} / \mathrm{s}$ respectively for fractions $50-75 \mu \mathrm{m}, 75-100 \mu \mathrm{m}$ and $100-140 \mu \mathrm{m}$, the CLC process can be carried out with a wide range of fluidising gas velocities. The minimum bubbling velocities are not much different from minimum fluidisation velocities, and they equal 1.1; 2.0; $3.5 \mathrm{~cm} / \mathrm{s}$ for fractions $50-75,75-100,100-140 \mu \mathrm{m}$. The bubbles are not beneficial for the CLC process. The bubbles diameter do not exceed $3 \mathrm{~mm}$ at the outlet from the gas distributor. As the bed height increases, the bubbles grow and merge, and their sizes can be calculated from the known correlations. The reliability of bubble size calculations was confirmed by photographing a bubble flowing at the wall of the reactor.

\section{References}

1. D. S. Arndt, R. J. H. Dunn, T. Li, Bull. Am. Meteorol. Soc. 99 (2018)

2. K. S. Lackner, Science 300, 1677-1678 (2003)

3. A. Lyngfelt, B. Leckner, T. Mattisson, Chem. Eng. Sci. 56, 3101-3113 (2001)

4. J. Adanez, A. Abad, F. Garcia-Labiano, P. Gayan, L. F. de. Diego, Prog. Energy Combust. Sci. 38, 215-282 (2012)

5. Z. Gao, Z. Wu, W. Liu, J. Environ. Chem. Eng. 4, 1653-1663 (2016)

6. P. Baran, E. Klempka, P. Kowalik, K. Antoniak, Chem. Int. 66, 1108-1112 (2012)

7. C. Y. Wen, H. Yu, AIChE J. 12, 610-612 (1966) 